\title{
Enhancement of solubility and mass transfer coefficient of benzoic acid through hydrotropy
}

\author{
D. Gnana Prakash ${ }^{1 *}$, S. Thenesh Kumar², N. Nagendra Gandhi ${ }^{3}$ \\ ${ }^{1}$ Department of Chemical Engineering, SSN College of Engineering, Chennai-603 110, India. \\ ${ }^{2}$ Department of Chemical Engineering, Vel Tech High Tech Dr. Rangarajan Dr. Sakunthala Engineering College, Chennai \\ 600062, India \\ ${ }^{3}$ Department of Chemical Engineering, A. C. College of Technology, Anna University, Chennai - 600 025, India \\ *Corresponding author: gnanaprakashd@ssn.edu.in
}

\begin{abstract}
The effect of hydrotropes such as sodium salicylate, sodium benzoate, and nicotinamide on the solubility and mass transfer coefficient of benzoic acid has been investigated. The solubility studies were carried out under a wide range of hydrotrope concentrations ( 0 to $3.0 \mathrm{~mol} / \mathrm{L})$ and different system temperatures (303K to $333 \mathrm{~K})$. It has been observed that the solubility and mass transfer coefficient of benzoic acid increases with an increase in hydrotrope concentration and also with system temperature. A Minimum Hydrotrope Concentration (MHC) was found essential to initiate a significant increase in the solubility and the mass transfer coefficient. The maximum enhancement factor $\left(\varphi_{s}\right)$, which is the ratio of the solubility value in the presence and absence of a hydrotrope, has been determined for all sets of experimentations. The solubility of benzoic acid has been enhanced to 19.98 times in the presence of $2.5 \mathrm{~mol} / \mathrm{L}$ concentration of sodium salicylate hydrotrope at 333K. The effectiveness of hydrotropes was measured in terms of Setschenow constant $K_{s}$ and the highest value has been observed as 0.502 for sodium salicylate.
\end{abstract}

Keywords: hydrotropy, solubilization, mass-transfer coefficient, benzoic acid.

\section{INTRODUCTION}

Hydrotropy is a unique and unprecedented solubilization technique in which certain chemical compounds termed as hydrotropes can be used to effect a several fold increase in the solubility of sparingly soluble solutes under normal conditions ${ }^{1}$. This increase in solubility in water is probably due to the formation of organized assemblies of hydrotrope molecules at critical concentrations ${ }^{2,3}$.

Hydrotropes are water-soluble and surface-active compounds, which can significantly enhance the solubility of organic compounds, drugs, biochemicals and petro-products ${ }^{4-10}$. The solubility enhancement in the organic compounds could be due to the formation of molecular structures in the form of complexes. Easy recovery of dissolved solute and possible reuse of hydrotrope solutions makes this technique most attractive one particularly at industrial levels ${ }^{\mathbf{1 1}}$.

Besides the advantage of certain properties such as the solvent character being independent of $\mathrm{pH}$, non-flammability, easy availability of hydrotropes, inexpensive aqueous phase makes this method superior to other solubilization methods. Hydrotropy is a process which goes beyond other conventional solubilization methods such as miscibility, co-solvency, salting-in etc., since it offers high selectivity and unprecedented increase in solubility and mass transfer coefficient ${ }^{12,13}$. The problem of emulsification, which is normally encountered with surfactant solution, is not found with hydrotrope solution ${ }^{14,15}$. The effect of hydrotropes on the solubility and mass transfer coefficient for a series of organic compounds such as butyl acetate, ethyl benzoate, amyl acetate, methyl salicylate, benzyl acetate, salicylic acid, stearic acid and $p$-nitrobenzoic acid was studied in our earlier publications ${ }^{\mathbf{1 6}-22}$.

The poor solubility of many organic compounds in water is a major limiting factor in the development of chemical and pharmaceutical industry. Benzoic acid is one such organic compound which has low aqueous solubility but it has wide pharmaceutical and industrial applications. Benzoic acid and its derivatives are widely used in preservation of foods and fruit juices besides being used as an important component in the preparations of resins, plasticizers, dyes, inks, and pharmaceutical products ${ }^{23,24}$. Benzoic acid occurs naturally in many herbs, resins and even it is detected in animals ${ }^{25}$. Recent studies towards this direction show that various organic solvents and water at subcritical condition are used to increase the solubility of benzoic acid but their applications are limited either due to high operating cost and non-environment friendly solvents ${ }^{26-28}$. It has been observed that in many two-phase reaction systems involving a sparingly soluble organic compound like benzoic acid, the mass transfer coefficient was found to be very low solely due to the poor solubility of benzoic acid in the aqueous phase. Since benzoic acid serves as a raw material/intermediate for a wide variety of chemical, pharmaceutical and allied products and the separation of benzoic acid from any liquid mixture seems to be difficult, this hydrotropic technique can be adapted to increase the solubility as well as to separate such mixtures effectively.

\section{EXPERIMENTAL}

All the chemicals used in this work were procured from Himedia Chemicals, Mumbai (AR grade) with a manufacturer's stated purity of $99 \%$. Distilled water was used throughout the experiments for preparing various concentrations of hydrotrope solutions. For each solubility test, an excess amount of benzoic acid was added to the hydrotrope solution of a known concentration in the separating funnel placed in the thermostatic bath fitted with temperature controller capable of maintaining temperature within $\pm 0.1^{\circ} \mathrm{C}$. The separating funnel was sealed to avoid evaporation of the solvent at higher temperatures. The setup was kept overnight for equilibration. After equilibrium was attained, the solution was 
filtered using Whatman filter paper to remove the excess of the undissolved benzoic acid. The concentration of the dissolved organic acid in aqueous hydrotrope solutions was analyzed by titrating against the standardized sodium hydroxide solution using phenolphthalein solution as an indicator. Blank titration was carried out and necessary correction was done to calculate the dissolved organic acid in aqueous hydrotrope solutions. All the solubility experiments were conducted in duplicate to check the reproducibility. The observed error in the reproducibility of experimental results was less than $2 \%$.

The experimental setup for the determination of the mass transfer coefficient consisted of a vessel provided with baffles and a turbine impeller run by a motor to agitate the mixture. The vessel used for mass transfer studies is of height $40 \mathrm{~cm}$ and inner diameter $15 \mathrm{~cm}$. The turbine impeller diameter is $5 \mathrm{~cm}$, the width is $1 \mathrm{~cm}$, and the length is $1.2 \mathrm{~cm}$. It has four blades. The baffle is $40 \mathrm{~cm}$ high with a diameter of $1.5 \mathrm{~cm}$. It has four blades and rotates at $600 \mathrm{rpm}$.

For each run, to measure the mass transfer coefficient, an excess amount of benzoic acid was added to the aqueous solution of the hydrotrope of known concentration. The sample was then agitated for a known time of $600,1200,1800$ and 2400 seconds. After the end of fixed time $t$, the mixture was allowed to stand for some time. Then the solution was filtered from the remaining solid. The concentration of the solubilized organic acid in aqueous hydrotrope solutions at time $t$ was analyzed in the same way as done for solubility determinations. A plot of $-\log \left[1-\mathrm{C}_{\mathrm{b}} / \mathrm{C}^{*}\right]$ versus $t$ is drawn, where $\mathrm{C}_{b}$ is the concentration of benzoic acid at time $t$ and $\mathrm{C}^{*}$ is the equilibrium solubility of benzoic acid at the same hydrotrope concentration. The slope of the graph gives $\mathrm{k}_{\mathrm{L}} \mathrm{a} / 2.303$, from which $k_{\mathrm{L}} a$, the mass transfer coefficient was determined. Duplicate runs were made to check the reproducibility and the observed error was $<2 \%$.

The Scanning Electron Microscope (SEM) uses a beam of high energy electrons to generate a variety of signals at the surface of solid samples. The electron-sample interactions reveal information about the sample's surface topography. Signals produced by an SEM result from interactions of the electron beam with atoms at or near the surface of the sample. The relative narrower electron beam produced by SEM yields a characteristic three-dimensional appearance useful for investigating the surface of objects. The SEM is also capable of determining chemical composition, crystalline structure and crystal orientations. In the present study the samples of dried solubilized form of benzoic acid in water and benzoic acid in aqueous sodium salicylate solutions were examined by scanning electron microscopy at an accelerating voltage of $15 \mathrm{kV}$, using Hitachi VP-SEM S-3400 model.

\section{RESULTS AND DISCUSSION}

\section{Solubility}

The solubility of benzoic acid in water at $303 \mathrm{~K}$ is $3.21 \times 10^{-2} \mathrm{~mol} / \mathrm{L}$, which is in excellent agreement with the earlier reported values ${ }^{29-31}$. The experimental data representing the average of duplicate determinations on the effect of hydrotropes, i.e., sodium salicylate, sodium benzoate and nicotinamide on the solubility of benzoic acid are plotted in Figs. 1 to 3. It has been observed that the solubility of benzoic acid in water increases significantly only after the addition of 0.50 $\mathrm{mol} / \mathrm{L}$ of sodium salicylate in the aqueous solution. This concentration is referred to as the Minimum Hydrotrope Concentration (MHC) $)^{32}$.

Therefore, it is evident that hydrotropy was operational above the MHC of, sodium salicylate $(0.5 \mathrm{~mol} / \mathrm{L})$, sodium benzoate $(0.40 \mathrm{~mol} / \mathrm{L})$ and nicotinamide $(0.6$ $\mathrm{mol} / \mathrm{L}$ ) irrespective of system temperature. This MHC value assumes greater significance in the context of the recovery of benzoic acid from hydrotope solutions. Since hydrotropy appears to operate only at significant concentrations of hydrotrope in water, most hydrotropic solutions release the dissolved benzoic acid on dilution with water below MHC. The knowledge of MHC values is necessary especially at industrial levels, as it ensures

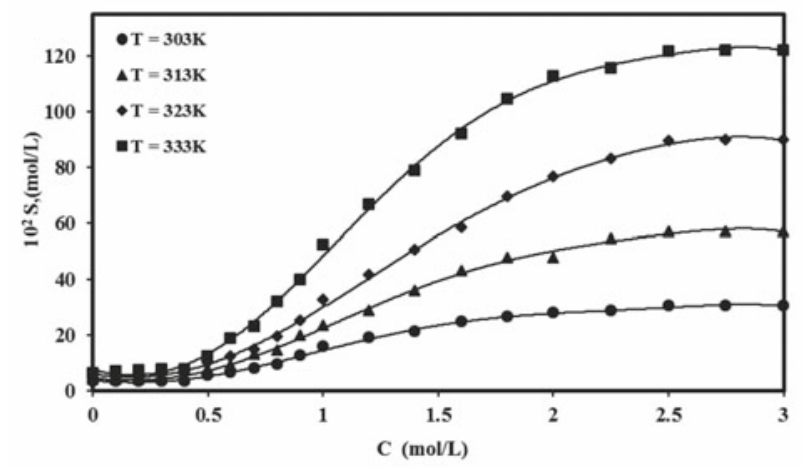

Figure 1. Effect of sodium salicylate concentration (C) on the solubility (S) of benzoic acid in water at different temperatures

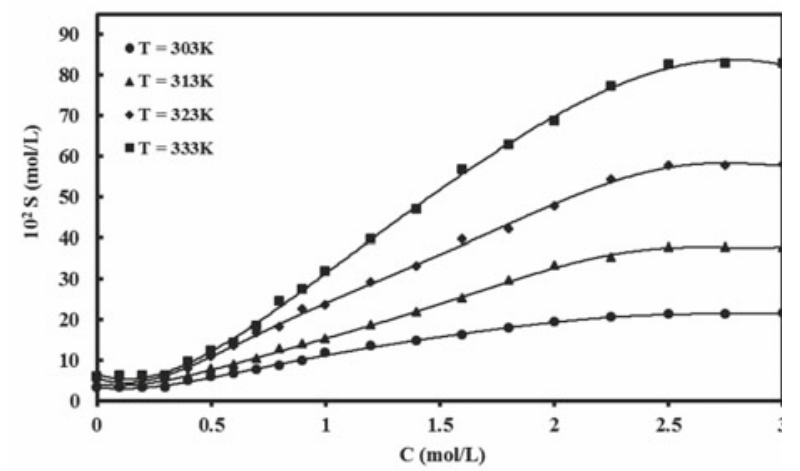

Figure 2. Effect of sodium benzoate concentration (C) on the solubility (S) of benzoic acid in water at different temperatures

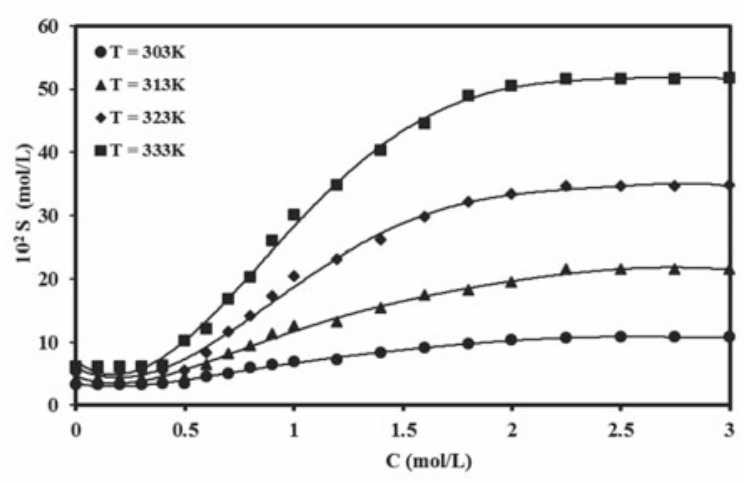

Figure 3. Effect of nicotinamide concentration (C) on the solubility (S) of benzoic acid in water at different temperatures 
ready recovery of the hydrotrope for reuse. The MHC values remained unaltered even at increased system temperatures.

The solubilization effect varies with concentration of hydrotropes. In the present case, a clear increasing trend in the solubility of benzoic acid was observed above the MHC of sodium salicylate. This increasing trend is maintained only up to a certain concentration of sodium salicylate in the aqueous solution, beyond which there is no appreciable increase in the solubility of benzoic acid. This concentration of sodium salicylate (hydrotrope) in the aqueous solution is referred to as the maximum hydrotrope concentration $\left(\mathrm{C}_{\max }\right)$. From the analysis of the experimental data, it is observed that further increase in hydrotrope concentration beyond $\mathrm{C}_{\max }$ does not bring any appreciable increase in the solubility of benzoic acid even up to $3.00 \mathrm{~mol} / \mathrm{L}$ of sodium salicylate in the aqueous solution. Similar to the MHC values, the $\mathrm{C}_{\max }$ values of hydrotropes also remained unaltered at increased system temperatures.

The knowledge of $\mathrm{MHC}$ and $\mathrm{C}_{\max }$ values of each hydrotrope with respect to a particular solute assumes greater significance in this study since it indicates the beginning and saturation of the solubilization effect of hydrotropes. The values of $\mathrm{MHC}$ and $\mathrm{C}_{\max }$ of a hydrotrope with respect to benzoic acid may be useful in determining the recovery of the dissolved benzoic acid even to an extent of the calculated amount from hydrotrope solutions at any concentration between $\mathrm{MHC}$ and $\mathrm{C}_{\max }$ by simple dilution with distilled water. This is the unique advantage of the hydrotropic solubilization technique.

From the experimental data plotted in Fig. 1, it can further be observed that, in order to achieve a particular solubility of benzoic acid say i.e., $20.0 \times 10^{-2} \mathrm{~mol} / \mathrm{L}$, it is required to maintain the concentration of sodium salicylate in the aqueous phase at $1.30 \mathrm{~mol} / \mathrm{L}$ for a system temperature of $303 \mathrm{~K}, 0.90 \mathrm{~mol} / \mathrm{L}$ for $313 \mathrm{~K}, 0.80 \mathrm{~mol} / \mathrm{L}$ for $323 \mathrm{~K}$ and $0.60 \mathrm{~mol} / \mathrm{L}$ for $333 \mathrm{~K}$. Therefore when the system temperature is increased, a lesser amount of hydrotrope concentration is adequate to achieve any particular solubility of benzoic acid. A similar trend has been observed for other systems also. It has also been observed that the solubilization effect of sodium salicylate was not a linear function of the concentration of the sodium salicylate. The solubilization effect of sodium salicylate increases with increase in hydrotrope concentration and also with system temperature ${ }^{33}$.

A similar trend has been observed in the solubilization effect of other hydrotropes namely sodium benzoate and nicotinamide. It has also been observed that the MHC values of hydrotrope used in this work range between 0.40 and $0.60 \mathrm{~mol} / \mathrm{L}$ (Table 1), which seem to depend on the hydrophilicity of a hydrotrope. As can be seen from Table $1, \mathrm{C}_{\max }$ values of sodium salicylate, sodium benzoate and nicotinamide are $2.50,2.50$ and $2.25 \mathrm{~mol} / \mathrm{L}$ respectively. The maximum solubilization enhancement factor $\left(\varphi_{s}\right)$, which is the ratio of solubility values in the
Table 1. MHC and $\mathrm{C}_{\max }$ values for hydrotropes

\begin{tabular}{|l|c|c|}
\hline Hydrotrope & $\mathrm{MHC}(\mathrm{mol} / \mathrm{L})$ & $\mathrm{C}_{\max }(\mathrm{mol} / \mathrm{L})$ \\
\hline Sodium salicylate & 0.50 & 2.50 \\
Sodium benzoate & 0.40 & 2.50 \\
Nicotinamide & 0.60 & 2.25 \\
\hline
\end{tabular}

presence and absence of a hydrotrope, ranges between 3.34 and 19.98. The lowest value of $\varphi_{s}$ (3.34) was observed in the presence of nicotinamide at a system temperature of $303 \mathrm{~K}$. The highest value of $\varphi_{s}(19.98)$ has been observed in the case of sodium salicylate at a system temperature of 333K (Table 2).

\section{Mass transfer coefficient}

The mass transfer coefficient of benzoic acid + water system in the absence of any hydrotrope was determined as $7.14 \times 10^{-4} \mathrm{~s}^{-1}$ at $303 \mathrm{~K}$ (Table 3). The effect of different hydrotropes on the mass transfer coefficient of benzoic acid at different hydrotrope concentrations is also given in the same table. It can be seen that a threshold value of $0.50 \mathrm{~mol} / \mathrm{L}$ is required to effect significant enhancement in the mass transfer coefficient of benzoic acid + water system, as observed in the case of solubility determinations. The mass transfer coefficient of benzoic acid + water system increases with increase in sodium salicylate concentration. Beyond a $\mathrm{C}_{\max }$ of $2.50 \mathrm{~mol} / \mathrm{L}$ there is no appreciable increase in the mass transfer coefficient of benzoic acid, as observed in the case of solubility determinations. The maximum enhancement factor for mass transfer coefficient of benzoic acid + water system in the presence of sodium salicylate was found to be 12.07 (Table 3). A similar trend in the mass transfer coefficient enhancement $\left(\varphi_{m t c}\right)$ of benzoic acid has been observed for other hydrotropes also namely sodium benzoate and nicotinamide. The reported mass transfer coefficient enhancement $\left(\varphi_{m t c}\right)$ of benzoic acid of hydrotrope solutions are 12.07 for sodium salicylate, 7.76 for sodium benzoate and 5.16 for nicotinamide at their maximum hydrotrope concentrations. The highest value of $\varphi_{m t c}$ (12.07) has been observed in the presence of sodium salicylate as hydrotrope at $\mathrm{C}_{\max }$ of $2.50 \mathrm{~mol} / \mathrm{L}$.

\section{Effectiveness of hydrotropes}

The effectiveness factor of each hydrotrope with respect to benzoic acid at different system temperatures has been determined by analyzing the experimental solubility data for each case applying the model suggested by Setschenow ${ }^{34}$ and later modified by Gaikar and Pathak (1993), as given by the equation

$\log \left[\mathrm{S} / \mathrm{S}_{\mathrm{m}}\right]=\mathrm{K}_{\mathrm{s}}\left[\mathrm{C}_{\mathrm{s}}-\mathrm{C}_{\mathrm{m}}\right]$

Where $\mathrm{S}$ and $\mathrm{S}_{\mathrm{m}}$ are the solubility of benzoic acid at any hydrotrope concentration $\mathrm{C}_{s}$ and the minimum hydrotrope concentration $\mathrm{C}_{m}$, respectively. The Setschenow constant $\mathrm{K}_{\mathrm{s}}$ can be considered as a measure of the effectiveness of a hydrotrope at any given conditions of hydrotrope concentration and system temperature. The Setschenow constant values of hydrotropes namely

Table 2. Maximum solubilization enhancement factor $\left(\varphi_{\mathrm{s}}\right)$ of benzoic acid

\begin{tabular}{|l|c|c|c|c|}
\hline \multirow{2}{*}{ Hydrotrope } & \multicolumn{4}{|c|}{ Maximum enhancement factor for solubility $\left(\varphi_{s}\right)$} \\
\cline { 2 - 5 } & $\mathrm{T}=303 \mathrm{~K}$ & $\mathrm{~T}=313 \mathrm{~K}$ & $\mathrm{~T}=323 \mathrm{~K}$ & $\mathrm{~T}=323 \mathrm{~K}$ \\
\hline Sodium salicylate & 9.43 & 14.07 & 16.16 & 19.98 \\
Sodium benzoate & 6.63 & 9.35 & 11.25 & 13.61 \\
Nicotinamide & 3.34 & 5.32 & 6.74 & 8.48 \\
\hline
\end{tabular}


Table 3. Effect of hydrotrope concentration (C) on the mass transfer coefficient $\left(\mathrm{k}_{\mathrm{L}} \mathrm{a}\right)$ of benzoic acid at $303 \mathrm{~K}$

\begin{tabular}{|c|c|c|c|}
\hline Hydrotrope & $\begin{array}{c}\mathrm{C} \\
(\mathrm{mol} / \mathrm{L})\end{array}$ & $\begin{array}{c}10^{4} \mathrm{k}_{\mathrm{L}} \mathrm{a} \\
\left(\mathrm{s}^{-1}\right)\end{array}$ & $\begin{array}{c}\text { Enhancemen } \\
t \text { factor for } \\
\text { mass transfer } \\
\text { coefficient } \\
\left(\varphi_{m t c}\right)\end{array}$ \\
\hline \multirow{15}{*}{$\begin{array}{l}\text { Sodium } \\
\text { salicylate }\end{array}$} & 0 & 7.14 & - \\
\hline & 0.2 & 7.25 & 1.02 \\
\hline & $0.5^{*}$ & 19.22 & 2.69 \\
\hline & 0.6 & 22.27 & 3.12 \\
\hline & 0.8 & 25.25 & 3.54 \\
\hline & 1.0 & 38.60 & 5.41 \\
\hline & 1.2 & 44.72 & 6.26 \\
\hline & 1.4 & 52.68 & 7.38 \\
\hline & 1.6 & 65.44 & 9.17 \\
\hline & 1.8 & 69.25 & 9.70 \\
\hline & 2.00 & 73.91 & 10.35 \\
\hline & 2.25 & 79.36 & 11.11 \\
\hline & $2.50^{\star *}$ & 86.21 & 12.07 \\
\hline & 2.75 & 86.48 & 12.11 \\
\hline & 3.00 & 87.21 & 12.21 \\
\hline \multirow{15}{*}{$\begin{array}{l}\text { Sodium } \\
\text { benzoate }\end{array}$} & 0 & 7.14 & - \\
\hline & 0.2 & 7.19 & 1.01 \\
\hline & $0.4^{*}$ & 16.61 & 2.33 \\
\hline & 0.6 & 17.82 & 2.50 \\
\hline & 0.8 & 19.24 & 2.69 \\
\hline & 1.0 & 23.85 & 3.34 \\
\hline & 1.2 & 25.61 & 3.54 \\
\hline & 1.4 & 28.94 & 4.05 \\
\hline & 1.6 & 31.39 & 4.40 \\
\hline & 1.8 & 36.86 & 5.16 \\
\hline & 2.00 & 45.95 & 6.44 \\
\hline & 2.25 & 49.05 & 6.87 \\
\hline & $2.50^{\star *}$ & 55.42 & 7.76 \\
\hline & 2.75 & 55.47 & 7.77 \\
\hline & 3.00 & 55.71 & 7.80 \\
\hline \multirow{15}{*}{ Nicotinamide } & 0 & 7.14 & - \\
\hline & 0.2 & 7.17 & 1.00 \\
\hline & 0.5 & 14.94 & 2.09 \\
\hline & $0.6^{*}$ & 18.25 & 2.56 \\
\hline & 0.8 & 21.16 & 2.96 \\
\hline & 1.0 & 25.89 & 3.63 \\
\hline & 1.2 & 27.54 & 3.86 \\
\hline & 1.4 & 30.45 & 4.26 \\
\hline & 1.6 & 32.84 & 4.60 \\
\hline & 1.8 & 33.98 & 4.76 \\
\hline & 2.00 & 34.75 & 4.87 \\
\hline & $2.25^{\star \star}$ & 36.84 & 5.16 \\
\hline & 2.50 & 37.12 & 5.20 \\
\hline & 2.75 & 37.18 & 5.20 \\
\hline & 3.00 & 37.51 & 5.25 \\
\hline
\end{tabular}

${ }^{*} \mathrm{MHC}$ : Minimum hydrotrope concentration

${ }^{* *} C_{\text {max }}$ : Maximum hydrotrope concentration

sodium salicylate, sodium benzoate and nicotinamide for benzoic acid + water system at different system temperatures are listed in Table 4. The highest value has been observed as 0.502 in the case of sodium salicylate as hydrotrope at $333 \mathrm{~K}$. The order of effectiveness of various hydrotropes based on $\mathrm{K}_{\mathrm{s}}$ values is given by sodium salicylate $>$ sodium benzoate $>$ nicotinamide.

\section{Microscopic studies}

The SEM images of the dried solubilized product of benzoic acid in water and aqueous sodium salicylate solution are shown in Figure 4 and 5 respectively. It was observed from Fig. 4 that the shape of benzoic acid crystal was needle like structure with sharp edges with irregular pattern. But the particles of dried solubilized form of benzoic acid in aqueous sodium salicylate solution were spherical and it has uniform particle size (Fig. 5). This clearly indicates that the benzoic acid has dissolved

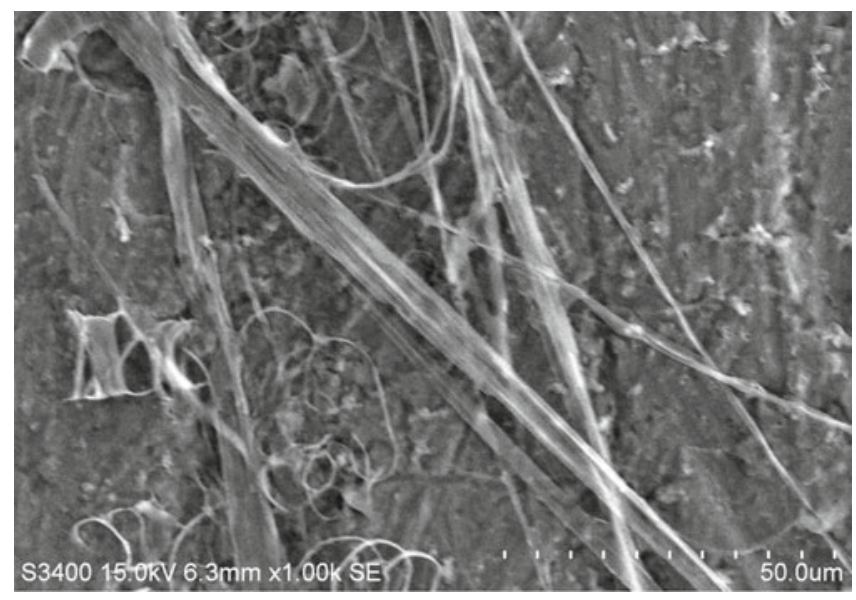

Figure 4. SEM images of dried solubilized form of benzoic acid in water

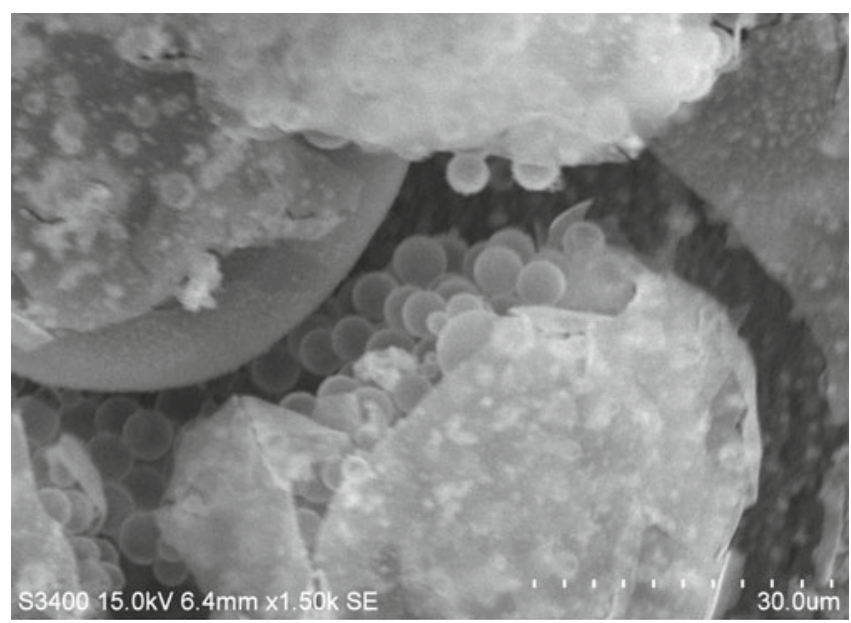

Figure 5. SEM images of dried solubilized form of benzoic acid in aqueous sodium salicylate solution

and recrystallized rather than just suspended. Thus the hydrotropy has enabled proper dissolution of benzoic acid.

\section{CONCLUSIONS}

The solubility of benzoic acid, which is slightly soluble in water, has been increased to a maximum value of $121.50 \times 10^{-2} \mathrm{~mol} / \mathrm{L}$ at $333 \mathrm{~K}$ with an enhancement factor of 19.98 times in the presence of sodium salicylate $(2.5 \mathrm{~mol} / \mathrm{L})$ as hydrotrope. The mass transfer coefficient was also found to increase to a maximum value of $86.21 \times 10^{-4} \mathrm{~s}^{-1}$ at $303 \mathrm{~K}$ and with an enhancement factor of 12.07 times in the presence of sodium salicylate $(2.5 \mathrm{~mol} / \mathrm{L})$ as hydrotrope. This would be useful in increasing the rate of an output

Table 4. Setschenow Constant $\left(\mathrm{K}_{\mathrm{s}}\right)$ of hydrotropes with respect to benzoic acid

\begin{tabular}{|l|c|c|c|c|}
\hline \multirow{2}{*}{ Hydrotrope } & \multicolumn{4}{|c|}{ Setschenow constant $\left(\mathrm{K}_{\mathrm{s}}\right)$} \\
\cline { 2 - 5 } & $T=303 \mathrm{~K}$ & $T=313 \mathrm{~K}$ & $T=323 \mathrm{~K}$ & $T=333 \mathrm{~K}$ \\
\hline Sodium salicylate & 0.376 & 0.438 & 0.474 & 0.502 \\
Sodium benzoate & 0.313 & 0.396 & 0.428 & 0.465 \\
Nicotinamide & 0.229 & 0.316 & 0.378 & 0.428 \\
\hline
\end{tabular}


of the desired product made from benzoic acid. The MHC and $\mathrm{C}_{\max }$ values of the hydrotrope with respect to benzoic acid can be used for the recovery of the dissolved benzoic acid and hydrotrope solutions at any hydrotrope concentration between the $\mathrm{MHC}$ and $\mathrm{C}_{\max }$ by simple dilution with distilled water. This will eliminate the huge cost and energy normally involved in the separation of the solubilized benzoic acid from its solution. The unprecedented increase in the solubilizing effect of hydrotropes is attributed to the formation of organized aggregates of hydrotrope molecules at a particular concentration.

\section{LITERATURE CITED}

1. Neuberg, C. (1916). Hydrotropy. Biochem. Z., 76: 107-108. 2. Balasubramanian, D., Srinivas V., Gaikar, V.G. \& Sharma, M.M. (1989). Aggregation Behaviour of Hydrotropic Compounds in Aqueous Solutions. J. Phys. Chem., 93, 3865-3870. DOI:10.1021/j100346a098.

3. Srinivas, V., Rodley, G.A., Ravikumar, K., Robinson, W.T., Turbull, M.M. \& Balasubramanian D. (1997). Molecular Organization in Hydrotrope Assemblies. Langmuir, 13: 3235-3239. DOI: $10.1021 / 1 a 9609229$.

4. Bodhankar, S.S., Rajaramani, V. \& Gaikar, V.G. (1998). Lipase Purification by Various Techniques and Its Thermo-Stability in the Presence of Surface Active Additives. J. Chem. Technol. Biotechnol., 71, 155-159. DOI: 10.1002/(SICI)1097-4660(199802)71:2<155::AID-JCTB824>3.0.CO;2-1.

5. Geeta, K.K., Tavare, N.S. \& Gaikar, V.G. (1991). Separation of $o / p$-Chloronitrobenzenes through Hydrotropy. Chem. Eng. Comm., 102, 211-224. DOI: 10.1080/00986449108910857.

6. Marimuthu, C., Jayakumar, C. \& Nagendra Gandhi, N. (2011). Study of hydrotropy-Petroleum and Petrochemical Products. Petroleum Science and Technology, 29, 337-348. DOI:10.1080/10916460903330106.

7. Gaikar, V.G. \& Phatak, P.V. (1999). Selective Solubilisation of Isomers in Hydrotrope Solution o-/p-Chlorobenzoic acids and o-/p-Nitro anilines. Sep. Sci. Technol., 34, 439-459. DOI:10.1081/ss-100100660.

8. Agrawal, S., Pancholi, S.S., Jain, N.K. \& Agrawal, G.P. (2004). Hydrotropic Solubilization of nimesulide for parenteral administration. Int. J. Pharm., 274 149-155. DOI:10.1016/j.ijpharm.2004.01.012.

9. Badwan, A.A., Khordagui, L.K.E. \& Salesh, A.M. (1982). The Solubility of Benzodiazepines in Sodium Salicylate Solutions and a Proposed Mechanism for Hydrotropic Solubilization. Int. J. Pharm., 13, 67-74. DOI:10.1016/0378-5173(82)90143-0.

10. Friberg, S.E., Yang, J. \& Huang, T. (1996). Reversible Extraction Process of Phenyl Ethyl Alcohol, a Fragrance. Ind. Eng. Chem. Res., 35, 2856-2859. DOI:10.1021/ie950661i.

11. Gaikar, V.G. \& Phatak, P.V. (1993). Solubility o- and p-Chlorobenzoic Acid in Hydrotrope Solutions. J. Chem. Eng. Data., 38: 217-220. DOI: 10.1021/je00010a007.

12. Dandekar, D.V. \& Gaikar, V.G. (2003). Hydrotropic Extraction of Curcuminoids from Turmeric. Sep. Sci. Technol., 38, 1185-1215. DOI:10.1081/SS-120018130.

13. Dandekar, D.V., Jayaprakasha, G.K. \& Patil, B.S. (2008). Hydrotropic extraction of bioactive limonin from sour orange (Citrus aurantium L.) seeds. Food Chem., 109, 515-520. DOI:10.1016/J.foodchem.2007.12.071.

14. Friberg, S.E. \& Brancewicz, C. (1994). O/W Microemulsions and Hydrotropes: The Coupling Action of a Hydrotrope. Langmuir, 10, 2945-2949. DOI: 10.1021/la00021a016.

15. Srinivas, V. \& Balasubramanian, D. (1998). When Does the Switch from Hydrotropy to Micellar Behavior Occur? Lagmuir. 14, 6658-6661. DOI: 10.1021/la980598c.

16. Nagendra Gandhi, N., Dharmendira Kumar, M. \& Sathyamurthy, N. (1998). Solubility and mass transfer coefficient enhancement of ethyl benzoate through hydrotropy. Hungarian J. Ind. Chem., 26, 63-68. http://www.vein.hu/HJIC/content/v26n1.html.
17. Meyyappan, N. \& Nagendra Gandhi, N. (2005). Solubility and mass transfer coefficient enhancement of benzyl benzoate in water through hydrotropy. J. Chem. Engg. Data, 50, 796-800. DOI:10.1021/je049756u.

18. Gnana Prakash, D., Thenesh Kumar, S. \& Nagendra Gandhi, N. (2009). Effect of hydrotropes on solubility and mass transfer coefficient of p-Nitrobenzoic acid. J. Applied Sci., 9, 2975-2980. DOI: 10.3923/jas.2009.2975.2980.

19. Thenesh Kumar, S., Gnana Prakash, D. \& Nagendra Gandhi, N. (2010). The effect of hydrotropes on the solubility and mass transfer coefficient of 2-nitrobenzoic acid. Pol. J. Chem. Tech., 11, 2, 55-59. DOI: 10.2478/v10026-009-0025-y.

20. Gnana Prakash, D., Thenesh Kumar, S. \& Nagendra Gandhi, N. (2010). Enhancement of solubility and mass transfer coefficient of 1,2-Dihydroxy-9,10-Anthraquinone (Alizarin) through hydrotropy. Chem. Eng. Comm., 197, 423-433. DOI: 10.1080/00986440903155998.

21. Thenesh Kumar, S., Gnana Prakash, D. \& Nagendra Gandhi, N. (2009). Effect of hydrotropes on solubility and mass transfer coefficient of Lauric acid. Korean J. Chem. Eng., 26: 1328-1333. DOI: 10.2478/s11814-009-0219-2.

22. Thenesh Kumar, S., Gnana Prakash, D. \& Nagendra Gandhi, N. (2010). Effect of hydrotropes on solubility and mass transfer coefficient of stearic acid. J. Chem. Eng. Data, 55, 2980-2984. DOI:10.1021/je90104n.

23. Warth, A.D. (1991). Mechanism of action of benzoic acid on Zygosaccharomvces bailii: effect on glycolytic metabolite level, energy production, and intracellular pH. Appl. Environ. Microbiol., 57, 3410-3414. PMCID: PMC183988.

24. John, R. Chipley. (2005). Antimicrobials in food. 3rd Edn., CRC Press, 11-48.

25. Pastrorova, I., De Koster, C.G. \& Boom, J.J. (1997). Analytic study of free and ester bound benzoic and cinnamic acids of gum benzoin resins by GC-MS HPLC-frit FABMS. Phytochem. Anal., 8, 63-73. DOI: 10.1002/(SICI)10991565(199703)8:2<63::AID-PCA337>3.0.CO;2-Y.

26. Amand, C., Oliveria., Marcia, G., Coelho., Ricardo, F., Pires.; Moilton, R. \& Franco, Jr. (2007). Solubility of benzoic acid in mixed solvents. J. Chem. Data, 52, 298-300. DOI: 10.1021/je060408x.

27. Jia Qingzhu, Ma Peisheng., Yi Shouzhi, Wang Qiang, Wang Chang \& Guiju, L.I. (2008). Solubilities of benzoic acid, p-Methylbenzoic acid, m-Methylbenzoic acid, o-Methylbenzoic acid, p-Hydroxybenzoic acid and o-Nitrobenzoic acids in 1-Octanol. J. Chem. Data, 53, 1278-1282. DOI: 10.1021/je700677d.

28. Berkant Kayan, Yu Yang, Edward, J., Lindquist \& Murat Gizir, A. (2010). Solubility of benzoic and salicylic acids in subcritical water at temperatrures ranging from (298 to 473) J. Chem. Eng. Data, 55, 2229-2232. DOI: 10.1021/je900769d.

29. Sahav, H., Kumar, S., Upadhyay, S.N. \& Upadhya, Y.D. (1981). Solubility of benzoic acid in aqueous polymeric solutions. J. Chem. Eng. Data, 26, 181-183. DOI: 10.1021/je00024a027.

30. Seidell, A. (1917). Solubilities of inorganic and organic substances. D.Van Nostrand: New York.

31. Kannan, A. \& Pathan, S.K. (2004). Enhancement of solid dissolution process. Chem. Eng. J., 102, 45-49. DOI:10.1016/j. cej.2004.01.022.

32. Miguel, G.N.,Carla C.S.,Katia R.P., \& Beatriz, E.G. (2007). The photophysical determination of the minimum hydrotrope concentration of aromatic hydrotropes. J. Colloid and Interface Sci., 315, 810-813. DOI: 10.1016/j.jcis.2007.02.020.

33. Wagle, V.B., Kothari, P.S. \& Gaikar, V.G. (2007). Effect of temperature on aggregation behaviour of aqueous solution of sodium cumene sulfonate. J. Mol. Liq., 133, 68-76. DOI: 10.1016/j.molliq.2006.07.006.

34. Huerta-Diaz, M.A. \& Rodriguez, S. (1992). Solubility measurements and determination of Setschenow constants for the pesticide carbaryl in seawater and other electrolyte solutions. Can. J. Chem., 70, 2864-2868. DOI: 10.1139/v92-365. 